\title{
Creatine supplementation as an exercise performance enhancer for patients with COPD? An idea to run with
}

\author{
T L Griffiths, D Proud
}

\section{Creatine supplementation may enhance pulmonary rehabilitation in patients with COPD, but larger trials are needed}

M ultidisciplinary pulmonary rehabilitation now has an established place in the management of chronic disabling respiratory diseases, particularly chronic obstructive pulmonary disease (COPD). ${ }^{1}$ Rehabilitation is being taken up widely on the strength of the accumulated evidence. While the effectiveness of rehabilitation is accepted, there is still considerable interest in refining and researching the individual modalities of treatment that make up the multidisciplinary intervention.

Exercise training is a key component of an effective pulmonary rehabilitation programme. In recent years a number of approaches have been taken in an effort to enhance the effectiveness of physical training, particularly for more severely disabled patients who may have reduced muscle bulk and whose baseline exercise capacity is particularly low. Broadly, strategies have either concentrated on acute interventions that enable subjects to train at higher intensity or have focused on altering underlying skeletal muscle functioning. An example of the former approach is the inclusion of oxygen supplementation during training in patients with hypoxaemia. ${ }^{2}$ Acute oxygen supplementation does enhance exercise performance and allows a higher work output for training. However, its use in training programmes has not been found to improve the overall outcomes of rehabilitation. Taking the alternative approach, attempts to restore muscle function have seen a crossover of techniques used for performance enhancement in sport and other areas of medicine. These interventions have included nutritional supplementation, ${ }^{4}$ the use of anabolic steroids, ${ }^{5}$ and the use of growth hormone. ${ }^{6}$ These kinds of intervention do increase muscle bulk but do not tend to produce beneficial gains in terms of whole body exercise and patient based outcomes in patients disabled by COPD and low muscle mass.
The underlying causes of the reduction in muscle mass in patients with COPD are likely to be heterogeneous and complex. They include imbalance in caloric intake and expenditure, disuse, the systemic effects of glucocorticoid steroid treatment, low circulating androgen levels, and systemic inflammation. The high prevalence of low muscle mass in patients with COPD is now recognised, as is the adverse impact of malnutrition in terms of disability, health service usage, and mortality. ${ }^{7}$

\section{THERAPEUTIC USE OF CREATINE SUPPLEMENTATION}

Set alongside these developments, there has been a growing interest in recent years in the potential for creatine supplementation to benefit various patient groups. When used as a dietary supplement, creatine monohydrate increases the availability of phosphocreatine in skeletal muscle. Phosphocreatine contributes a store of high energy phosphate bonds available at the onset of exercise. Following dephosphorylation, the creatine then becomes available for subsequent regeneration of phosphocreatine. A further effect of creatine is to increase fat-free mass by mechanisms that are not fully understood but which may have to do with muscle water content. In view of these effects, creatine monohydrate has become widely used to enhance athletic exercise performance, particularly in activities characterised by short bursts of activity rather than sustained effort. As with other interventions, creatine supplementation has also made the jump to application in disease states.

In a recent review of therapeutic creatine supplementation, Terjung et $a l^{8}$ highlighted a number of conditions including neuromuscular diseases where possible benefits to exercise capacity, muscle strength, and muscle mass may be seen. Mathews et $a l^{9}$ reported potential neuroprotective effects related to oxidative stress in an animal model of Huntington's disease. ${ }^{9}$ The potential for improved cardiac function and skeletal muscle performance in congestive heart failure with creatine supplementation has also been studied. ${ }^{10}$ The direct effect of creatine supplementation on lung function, enzymatic activity, and muscle strength in patients with cystic fibrosis has recently been reported in a pilot study. ${ }^{11}$ The authors concluded that, although no change in lung function or enzymatic activity in respiratory epithelial cells was evident, improvements in muscle strength and general wellbeing were seen. A number of studies have addressed the potential benefits of creatine supplementation in the elderly. Although most studies have failed to find significant effects, ${ }^{12}$ a more recent study $^{13}$ identified significant increases in muscle strength, fat free mass, and total body mass when creatine supplementation was offered in combination with resistance training.

\section{CREATINE SUPPLEMENTATION IN COPD}

With this background, it is perhaps surprising that the effect of creatine supplementation on muscle mass and muscle function in patients with COPD has been very little researched. This situation begins to be remedied by a paper in this issue of Thorax.

Fuld and colleagues ${ }^{14}$ report a randomised controlled trial of creatine monohydrate supplementation as an adjunct to exercise training in patients with moderately severe COPD. Their subjects received a standard 2 week loading regimen followed by a maintenance dose of creatine monohydrate or placebo in a randomised double blind fashion. After the loading phase, subjects participated in an exercise training programme of two sessions per week for 16 weeks. Training sessions included mobility and strength training together with 20 minutes of endurance training on a static bike. The primary outcome variable was 10 metre incremental shuttle walk distance. Secondary outcomes were body composition, muscle strength, and cardiopulmonary responses to incremental exercise testing and disease specific health status. Although this was essentially a negative study with respect to its primary outcome variable, the authors present intriguing secondary outcome data. Firstly, fatfree mass increased on average by $1.1 \mathrm{~kg}$ in the creatine supplemented group, significantly more than in the placebo group after the loading phase. At the same time, significant benefits in indices of upper and lower limb muscle functioning were seen in the creatine group compared with the 
placebo group. While the findings for isolated muscle work were consistent, no discernible trend or significance for between-group differences was seen in response to whole body exercise, either on the cycle ergometer or corridor walking tests. Thus, once again, apparent benefits at a muscle level were not translated into improvements in the integrated response to whole body exercise. Outcomes following exercise training while continuing creatine supplementation were compared with the pre-creatine baseline. Improvements were seen in terms of fat-free mass and limb muscle functioning following training in both groups, but the gap between the creatine supplemented and placebo groups widened. Again, indices of the response to cycling and walking exercise changed inconsistently. Shuttle walking tests showed significant improvements after training but without appreciable differences between groups. Perhaps the most tantalising finding of the study is the significantly greater improvement seen in the creatine supplemented group in St George's Respiratory Questionnaire (SGRQ) score after training. There are certainly problems in interpreting the results from this questionnaire in groups of patients as small as 11 . However, the suggestion that creatine supplementation can lead to improvements in health status while improving individual muscle function independently of any effect on walking capacity is of great interest.

\section{IMPLICATIONS OF STUDY}

Everyday life is a series of varying transitions from one level of exercise to another and does not often approximate to the conditions of an incremental or endurance shuttle walk test. The physiological effect of creatine is postulated to be as a result of increased ready availability of high energy phosphate bonds within the muscles. These can be used to sustain work rate increases anaerobically until increased oxygen delivery to the muscle can sustain oxidative metabolism and eventually repay the oxygen deficit. The effect of creatine supplementation might therefore support the bioenergetic response to changes in work output. It might be that improving the "flexibility" of response to short step changes in work output is what is driving improvements in health status in this study. While this is an attractive hypothesis, there is a problem with the confident interpretation of the present study. Exercise training was accompanied by a surprising decrement in SGRQ scores in the non-supplemented group, whereas clinically important improvements were seen in the creatine supplemented group. In a group of patients prone to exacerbation and unexpected changes in health, much larger numbers of subjects would be needed to provide results confidently applicable to the generality of COPD patients. Additionally, this study begs the question as to whether similar effects would be seen in the context of multidisciplinary rehabilitation rather than pure exercise training.

Thus, as many questions are raised as are answered in the study reported by Fuld and colleagues. However, there is a prime facie case to answer as to whether creatine supplementation will indeed enhance the outcome of pulmonary rehabilitation in its more usual multidisciplinary format. The challenge now is to undertake a large randomised controlled trial, powered to detect clinically important differences in health status, to test this hypothesis. We will then be able to determine the potential usefulness of creatine supplementation in the context of multidisciplinary pulmonary rehabilitation for patients disabled by COPD.

Thorax 2005;60:525-526.

doi: $10.1136 /$ thx.2004.034355

\section{Authors' affiliations}

T L Griffiths, Wales College of Medicine,

Cardiff University, Llandough Hospital,

Penarth CF64 2XX, UK

D Proud, Pulmonary Rehabilitation Unit, Llandough Hospital, Penarth CF64 2XX, UK
Correspondence to: $\operatorname{Dr} T \mathrm{~L}$ Griffiths, Wales College of Medicine, Cardiff University, Llandough Hospital, Penarth, CF64 2XX, UK; griffithst@@cf.ac.uk

No conflicts of interest to declare

\section{REFERENCES}

1 Lacasse Y, Brosseau L, Milne S, et al. Pulmonary rehabilitation for chronic obstructive pulmonary disease. Cochrane Database of Systematic Reviews 2003.

2 Rooyackers J, Dekhuijzen P, van Hardwaarden C, et al. Training with supplemental oxygen in patients with COPD and hypoxaemia at peak exercise. Eur Respir J 1997; 10:1278-84.

3 Garrod R, Paul E, Wedzicha J. Supplemental oxygen during pulmonary rehabilitation in patients with COPD with exercise hypoxaemia. Thorax 2000;55:539-43.

4 Steiner M, Barton R, Singh S, et al. Nutritional enhancement of exercise performance in chronic obstructive pulmonary disease: a randomised controlled trial. Thorax 2003;58:745-51.

5 Creutzberg E, Wouters E, Mostert R, et al. Role for anabolic steroids in the rehabilitation of patients with COPD? A double-blind, placebo-controlled, randomized trial. Chest 2003;124:1733-42.

6 Burdet L, de Muralt B, Schutz Y, et al. Administration of growth hormone to underweight patients with chronic obstructive pulmonary disease. A prospective, randomized, controlled study. Am J Respir Crit Care Med 1997; 156:1800-6.

7 Landbo C, Prescott E, Lange P, et al. Prognostic value of nutritional status in chronic obstructive pulmonary disease. Am J Respir Crit Care Med 1999;160:1856-61.

8 Teriung RL, Clarkson P, ER E, et al. The physiological and health effects of oral creatine supplementation. Med Sci Sport Exerc 2000;32:706-17.

9 Mathews RT, Yang L, Jenkins BG, et al. Neuroprotective effects of creatine and cyclocreatine in animal models of Huntington's disease. J Neurosci 1998;18:156-63.

10 Gordon A, Hultman E, Kaijser L, et al. Creatine supplementation in chronic heart failure increases skeletal muscle creatine phosphate and muscle performance. Cardiovasc Res 1995;30:413-8.

11 Braegger CP, Schlattner U, Wallimann T, et al. Effects of creatine supplementation in cystic fibrosis: results of a pilot study. J Cystic Fibrosis 2003;2: 177-82.

12 Tarnopolsky MA. Potential benefits of creatine monohydrate supplementation in the elderly. Curr Opin Clin Nutr Metabol Care 2000;3:497-502.

13 Brose A, GP, Tarnopolsky MA. Creatine supplementation enhances isometric strength and body composition improvements following strength exercise training in older adults. J Gerontol 2003;58: 11-9.

14 Fuld JP, Kilduff LP, Neder JA, et al. Creatine supplementation during pulmonary rehabilitation in chronic obstructive pulmonary disease. Thorax 2005;60:531-7. 
Smoking and tuberculosis

\section{Smoking and tuberculosis: a chance or causal association?}

\section{G H Bothamley}

\section{Possible explanations for the association between smoking and tuberculosis}

n 1956 Doll and Hill' wrote that "the relationship between smoking and mortality from pulmonary tuberculosis is distinct, but with a disease so influenced by social factors more precise data are needed to justify a direct cause and effect hypothesis".

The essential risk factors for human tuberculosis are (1) the tubercle bacillus, (2) a susceptible host, and (3) an environment which allows the tubercle bacilli to survive transit from one host to the next. All other risk factors are subsumed under these headings. If smoking is a risk factor for tuberculosis, then it must act by increasing the susceptibility of the human host or the probability of transmission by encouraging infectious individuals to cough (this requires smoking to be a social as much as an individual pursuit). If the association between smoking and tuberculosis is more apparent than real, then smoking may be a pointer to other risk factors. These include social class-itself a marker for overcrowding, poor ventilation and rooms with no natural light as well as poor nutrition-general ill health and, increasingly, HIV infection with prostitution and intravenous drug use.

\section{TUBERCULIN SENSITIVITY AND SMOKING}

Tuberculous infection and tuberculosis as a disease are entirely different states. The former is commonly characterised by tuberculin reactivity (despite the known problem of exposure to nontuberculous mycobacteria and the cross reactivity of the mixture of antigens ${ }^{2}$ ). Approximately one third of the world's population may be infected with the tubercle bacillus, but only eight million $(0.4 \%)$ develop tuberculosis each year.

Studies conflict as to whether smoking affects delayed hypersensitivity to tuberculin. Kuemmerer and Comstock ${ }^{3}$ noted that tuberculin reactions were greater in children where both parents smoked, but they also observed that education, urban residence, immigration, and overcrowding were significant associations. Although the Heaf test grade was found to be directly related to pack-years of smoking in residential homes for the elderly in the UK, social class was not determined as a possible confounding factor. ${ }^{4}$ A similar study in Hong Kong showed no association with smoking, ${ }^{5}$ while a survey of Vietnamese immigrants in Australia suggested a positive association between tuberculin responses and smoking history. ${ }^{6}$ In Norway, linear regression analysis associated smoking and male sex with greater tuberculin reactivity. ${ }^{7}$ In a study in Kuwait tuberculin reactivity was greater in smokers, and univariate analysis of variance showed a dose-response to pack-years in healthy controls but not in patients with tuberculosis. ${ }^{8}$ None of these studies accounted for socioeconomic status and its possible confounding effect on smoking and tuberculosis.

In this issue of Thorax a study by Den Boon et $a l^{9}$ in a socially homogeneous group again shows that tuberculin reactivity can be related to smoking, especially if this constituted more than 15 pack-years. More interestingly, a prospective study in the United States examined whether smokers were more likely to have developed a positive tuberculin reaction while in prison. ${ }^{10}$ Only those who had smoked for more than 15 years were more likely to show tuberculin conversion (relative risk 2.12, $95 \%$ confidence interval 1.03 to 4.36 ). The authors concluded that the cumulative effect of prolonged smoking was more significant than the number of cigarettes smoked in increasing the likelihood of infection by Mycobacterium tuberculosis in prison. The broad confidence intervals, with the lower figure giving an attributable risk of $<3 \%$ to smoking for tuberculin conversion, recommend a further study with greater power and with an assessment of the duration of imprisonment. Exposure to $M$ avium-intracellulare is common in the southern United States and may affect tuberculin conversion. Concurrent HIV infection is more common in those aged 20-35 years and might also confound tuberculin sensitivity. A future prospective study would need to examine the social behaviour of chronic smokers and the likelihood of the index case being within those who have smoked for $>15$ years.

The evidence to support a direct effect of smoking on tuberculin reactivity is therefore poor.

\section{SMOKING AND TUBERCULOSIS}

As already mentioned, tuberculosis as a disease is very different from tuberculous infection, defined by a positive tuberculin response. Several studies, beginning in 1956, have linked smoking with tuberculosis (reviewed by Maurya et $a l^{11}$ ). As in a more recent study, ${ }^{12}$ the possible confounding of socioeconomic factors with both smoking and tuberculosis has only occasionally been examined. ${ }^{13} \mathrm{Yu}$ et $a l^{14}$ used binomial regression to propose that heavy smoking was associated with pulmonary tuberculosis, although both were associated with male sex and increasing age. A case-control study matching street based postcode, sex, date of birth, and ethnic origin in Liverpool suggested that smoking for $>30$ years was associated with the development of all forms of tuberculosis, ${ }^{15}$ but this was not significant when corrected for the number of factors examined. Prospective evaluation of 42655 individuals registered with the Elderly Health Service in Hong Kong noted that pulmonary tuberculosis was more common in current smokers than in ex-smokers, and both were more common than in never smokers. Cox proportional hazards analysis accounted for 18 potential confounding factors including alcohol and several relating to socioeconomic status. There was also a dose-response relationship in current smokers for the development of pulmonary tuberculosis. A small study of contacts of sputum smear positive tuberculosis compared 46 adult patients with culture positive pulmonary tuberculosis and 46 tuberculin positive subjects without active tuberculosis. ${ }^{16}$ Adjusting the odds ratios for age, sex, and socioeconomic status demonstrated a dose-response relationship between the number of cigarettes smoked and the risk of active pulmonary tuberculosis. A similar study from the same group compared children in contact with tuberculosis who later developed the disease with those who remained well during the period of study despite a positive tuberculin skin test. ${ }^{17}$ Passive smoking, as assessed from the smoking history of the adult case and from urinary cotinine levels, was associated with a risk of developing pulmonary tuberculosis ( $\sim 80 \%$ primary complex disease). One would have to postulate that the infectious load, related to coughing behaviour of the smoking adult and using cotinine levels 
as a marker of proximity of the adult, was significant if passive smoking itself was not the significant factor in the development of active tuberculosis. The data are consistent with the hypotheses that both a long duration of smoking and current smoking might be related to the development of active pulmonary tuberculosis.

\section{EFFECTS OF SMOKING AND THE IMMUNE RESPONSE IN THE LUNG}

The alveolar macrophage is probably the first cell to ingest a tubercle bacillus following infection. These cells suppress the local immune response in order to preserve lung architecture. ${ }^{18}$ Silicosis is associated with an increased incidence of tuberculosis, suggesting that proper function of these cells is protective. Smoking impairs the phagocytic function of alveolar macrophages. ${ }^{19}$ Both smoking and tuberculosis induce apoptosis of these cells. ${ }^{20} 21$ However, smoking quadruples the number of macrophages that can be harvested by bronchial lavage. ${ }^{22}$ Cigarette smoke activates alveolar macrophages to produce a local inflammatory response, ${ }^{23}$ but nicotine suppresses the antigen presentation function to develop a specific immune response. ${ }^{24}$ Chronic exposure to cigarette smoke reduces expression of surface proteins related to antigen presentation by pulmonary macrophages. ${ }^{25}{ }^{26}$ Others have suggested that human alveolar type II pneumocytes may be the first port of call for the tubercle bacillus, ${ }^{27}$ but again this site of infection may promote innate over specific immunity. ${ }^{28}$ Smoking is not yet known to affect the expression of significant surface proteins in these cells.

Interleukin-18 (previously known as interferon- $\gamma$ inducing factor) is reduced in induced sputum from smokers. ${ }^{29}$ Nicotine impairs antigen receptor mediated signal transduction ${ }^{30}$ and induces $\mathrm{T}$ cell anergy. ${ }^{31}$ Natural killer cell activity is also less and significantly suppressed by alveolar macrophages from bronchoalveolar lavage fluid of smokers compared with non-smokers. ${ }^{32}$

\section{CONCLUSION}

The association of smoking with pulmonary tuberculosis might be explained by a reduced specific immunity and possibly enhanced non-specific inflammatory response. Such a model would predict that smoking during exposure to tubercle bacilli is less likely to induce delayed hypersensitivity but more likely to produce disease. If correct, any increase in tuberculin sensitivity associated with smoking would have to be explained by social behaviour rather than the host response.

Thorax 2005;60:527-528.

doi: $10.1136 /$ thx.2004.036012

Correspondence to: Dr G H Bothamley, NE London TB Network, Homerton University Hospital, London E9 6SR, UK; graham. bothamley@homerton.nhs.uk

\section{REFERENCES}

1 Doll R, Hill $A B$. Lung cancer and other causes of mortality in relation to smoking; a second report on the mortality of British doctors. BM 1956;12:1071-81.

2 Comstock GW, Daniel TM, Snider Jr DE, et al. The tuberculin skin test. Am Rev Respir Dis $1981 ; 124: 356-63$.

3 Kuemmerer JM, Comstock GW. Sociologic concomitants of tuberculin sensitivity. Am Rev Respir Dis 1967;96:885-92.

4 Nisar M, Williams CS, Ashby D, et al. Tuberculin testing in residential homes for the elderly. Thorax 1993;48:1257-60

5 Woo J, Chan HS, Hazlett CB, et al. Tuberculosis among elderly Chinese in residential homes: tuberculin reactivity and estimated prevalence. Gerontology 1996;42:155-62.

6 Plant AJ, Watkins RE, Gushulak B, et al. Predictors of tuberculin reactivity among prospective Vietnamese migrants: the effect of smoking. Epidemiol Infect 2002; 128:37-45.

7 Jentoft HF, Omenaas E, Eide GE, et al. Tuberculin reactivity: prevalence and predictors in BCGvaccinated young Norwegian adults. Respir Med 2002;96:1033-9.

8 Abal AT, Nair PC, Sugathan TN, et al. Influence of smoking on cutaneous delayed-type hypersensitivity reactions by tuberculin skin test. Respir Med 2003;97:672-5.

9 Den Boon S, van Lill SWP, Borgdorff MW, et al. Association between smoking and tuberculosis infection: a population survey in a high tuberculosis incidence area. Thorax 2005;60:555-7.

10 Anderson RH, Sy FS, Thompson S, et al. Cigarette smoking and tuberculin skin test conversion among incarcerated adults. Am J Prev Med 1997; 13:175-81.

11 Maurya V, Vijayan VK, Shah A. Smoking and tuberculosis: an association overlooked. Int J Tuberc Lung Dis 2002;6:942-51.

12 Gajalakshmi V, Peto R, Kanaka TS, et al. Smoking and mortality from tuberculosis and other diseases in India: retrospective study of 43000 adult male deaths and 35000 controls. Lancet 2003;362:507-15.

13 Gupta I, Sankar D. Tobacco consumption in India: a new look using data from the National Sample Survey. J Public Health Policy 2003;24:246-50.

14 Yu GP, Hsieh CC, Peng J. Risk factors associated with the prevalence of pulmonary tuberculosis among sanitary workers in Shanghai. Tubercle 1988;69:105-12.

15 Tocque K, Bellis MA, Beeching NJ, et al. A case control study of lifestyle risk factors associated with tuberculosis in Liverpool, North-West England. Eur Respir J 2001;18:959-64.

16 Alcaide J, Altet MN, Plans P, et al. Cigarette smoking as a risk factor for tuberculosis in young adults: a case-control study. Tuberc Lung Dis 1996;77:112-6.

17 Altet MN, Alcaide J, Plans P, et al. Passive smoking and risk of tuberculosis in children immediately following infection. A case-control study. Tuberc Lung Dis 1996;77:537-44.

18 Upham JW, Strickland DH, Bilyk N, et al. Alveolar macrophages from humans and rodents selectively inhibit T-cell proliferation but permit Tcell activation and cytokine secretion. Immunology 1995;84:142-7.

19 Elssner A, carter JE, Yunger TM, et al. HIV-1 infection does not impair human alveolar macrophage phagocytic function unless combined with cigarette smoking. Chest 2004;125:1071-6.

20 Aoshiba K, Tamaoki J, Nagai A. Acute cigarette smoke exposure induces apoptosis of alveolar. macrophages. Am J Physiol Lung Cell Mol Physiol 2001;281:L1392-401.

21 Keane J, Balcewicz-Sablinska MK, Remold HG, et al. Infection by Mycobacterium tuberculosis promotes human alveolar macrophage apoptosis. Infect Immun 1997;65:298-304.

22 Harris JO, Swenson EW, Johnson JE. Human alveolar macrophages: comparison of phagocytic ability, glucose utilization and ultrastructure in smokers and non-smokers. J Clin Invest 1970;69:2086-96.

23 Kirkham PA, Spooner G, Ffoulkes-Jones C, et al. Cigarette smoke triggers macrophage adhesion and activation of lipid peroxidation products and scavenger receptor. Free Radic Biol Med 2003;35:697-710.

24 Nouri-Shirazi $M$, Guinet E. Evidence for the immunosuppressive role of nicotine on human dendritic cell functions. Immunology 2003;109:365-73.

25 Pankow W, Neumann K, Ruschoff J, et al. Reduction in HLA-DR antigen density on alveolar macrophages. Lung 1991;169:255-62.

26 Skold CM, Lundahl J, Hallden G, et al. Chronic smoke exposure alters the phenotype pattern and the metabolic response in human alveolar macrophages. Clin Exp Immunol 1996;106:108-13.

27 Bermudez LE, Goodman J. Mycobacterium tuberculosis invades and replicates within type II alveolar cells. Infect Immun 1996;64:1400-6.

28 Schulz C, Kratzel K, Wolf K, et al. Activation of bronchial epithelial cells in smokers without airways obstruction and patients with COPD. Chest 2004;125:1706-13.

29 McKay A, Komai-Koma M, Macleod KJ, et al. Interleukin-18 levels in induced sputum are reduced in asthmatic and normal smokers. Clin Exp Allergy 2004;34:904-10.

30 Geng $Y$, Savage SM, Johnson $\sqcup$, et al. Effects of nicotine on the immune response. I. Chronic exposure to nicotine impairs antigen-receptor mediated signal transduction in lymphocytes. Toxicol Appl Pharmacol 1995; 135:268-78.

31 Geng Y, Savage SM, Razani-Boroujerdi S, et al. Effects of nicotine on the immune response. II. Chronic nicotine treatment induces T cell anergy. J Immunol 1996; 156:2384-90.

32 Tkeuchi M, Nagai S, Nakajima A, et al. Inhibition of lung natural killer cell activity by smoking: the role of alveolar macrophages. Respiration 2001;68:262-7. 
Neutrophils and asthma

\section{Is the neutrophil the key effector cell in severe asthma?}

A V Kamath, I D Pavord, P R Ruparelia, E R Chilvers

\section{The importance of the neutrophil as the dominant inflammatory cell in many of the non-atopic and more severe phenotypes of asthma is now clear}

$E$ sinophilic inflammation has long been considered one of the most distinctive pathological hallmarks of asthma ${ }^{1}$ and features in many contemporary definitions of this disease. A plethora of studies published from the mid 1990s onwards have suggested, however, that airway eosinophilia is not a universal finding. This has fuelled debate that discrete pathological phenotypes of asthma may exist, with the neutrophil-rather than the eosinophildominating in certain circumstances. ${ }^{2-4}$ We present data that support the current renewed interest in the neutrophil as a primary driver of airways inflammation, particularly in the most severe forms of asthma. There are also some intriguing data to suggest that, when the eosinophil has been "red carded" and disappears from the inflamed airway, the neutrophil may be drawn in and act as the substitutegranulocyte.

The hypothesis that the eosinophil is the key effector cell involved in the pathogenesis of asthma has run into trouble for several reasons: (1) eosinophilic inflammation is present in the airway lumen of only $50 \%$ of asthmatic subjects; ${ }^{4}(2)$ even intense eosinophilic inflammation, as occurs in eosinophilic bronchitis, fails to induce asthma; ${ }^{5}$ (3) many asthma exacerbations occur in the absence of airway eosinophilia; (4) specific anti-eosinophil strategies-for example, anti-IL-5 and IL-12-are poorly efficacious in vivo; ${ }^{6-8}$ and (5) eosinophilic deficient mice have now been engineered and this modification has little impact on the airway pathology induced in response to ovalbumin sensitisation. ${ }^{9}$

A strong association has now been established between neutrophilic inflammation of the airways and severe asthma, ${ }^{10-12}$ corticosteroid resistant asthma, ${ }^{13-15}$ asthma exacerbations, ${ }^{2}$ nocturnal asthma, ${ }^{16}$ "asthma in smokers", ${ }^{17}$ occupational asthma, ${ }^{18}$ and "sudden onset" fatal asthma. ${ }^{19}$ It is noteworthy that, in the study by Little and colleagues $^{12}$ conducted in a group of 59 asthmatics, forced expiratory volume in l second $\left(\mathrm{FEV}_{1}\right)$ was inversely proportional to neutrophil numbers. These studies analysed neutrophil numbers in all airway compartments including the small airways and, where measured, neutrophil numbers correlated well with markers of neutrophil degranulation which implies that these cells are also activated. $.^{10} 121520-22$ These findings are of particular importance given the disproportionate health costs associated with treating patients with severe disease. ${ }^{23}$

These data set up a number of critical questions-namely:

- What are the principal drivers of neutrophil influx into asthmatic airways?

- Can any of the existing asthma treatments be implicated in airway neutrophilia?

- How do we quantify neutrophil trafficking in this disease?

- What are the most promising therapeutic options to inhibit this process?

It is now widely argued that certain physical triggers including viruses, lipopolysaccharides, and ozone may be more important inducers of airway neutrophilia than any primary immunological cause,,$^{21}$ and epithelial derived IL-8 again stands out as one of the most likely chemoattractants for neutrophils. ${ }^{25}$ While in severe disease eosinophils and neutrophils are usually found together, ${ }^{13}$ cross sectional studies suggest that neutrophils may gradually replace eosinophils in proportion to the severity and/or duration of the disease. ${ }^{10}$ This view is supported by the study of Hauber and co-workers ${ }^{26}$ who took bronchial wall and transbronchial biopsy specimens from a group of 12 asthmatics before and after treatment with HFA-flunisolide. They found a dramatic fall in the number of IL-5 and eotaxin mRNA positive cells and eosinophils in both the central and peripheral airways and a corresponding and equally marked rise in the number of neutrophils at these sites. A similar effect has been reported elsewhere ${ }^{27} 28$ and may reflect the widely cited capacity of corticosteroids to induce eosinophil apoptosis and phagocytic removal and yet inhibit the same process in neutrophils. ${ }^{29-31}$ The possibility that the airway neutrophilia develops as a primary pathological response and hence represents a distinct inflammatory phenotype is supported by studies which show that this subgroup of patients is non-atopic and has an impaired response to inhaled corticosteroids. ${ }^{14} 15$

One intriguing insight into the potential high state of flux of neutrophils in the airway wall is provided by the study of Martin et al ${ }^{16}$ who performed bronchial lavage in patients with nocturnal asthma and found a greater than threefold increase in the number of granulocytes in bronchoalveolar lavage (BAL) fluid samples at 04.00 hours compared with 16.00 hours. This suggests a high rate of turnover of these cells and implies that neutrophils may have a surprisingly short half life ( $<8$ hours) in asthmatic airways. The plasticity of the airway neutrophilia is further supported by experimental data obtained using an equine model of asthma where complete resolution of the neutrophilic airway response occurred over a matter of a few days following removal of the mouldy hay challenge. ${ }^{32}$ In this model the alveolar macrophages appeared to make a significant contribution to the clearance of apoptotic neutrophil corpses from within the airway lumen. Thus, if neutrophils do not reside within the asthmatic airways for protracted periods due to the presence of efficient natural clearance mechanisms, strategies designed to block influx-which presumably occurs at the post capillary venule level within the bronchial circulation-may be highly efficacious. Recent studies have revealed the pivotal role of the enzyme phosphoinositide 3kinase in controlling neutrophil migration, activation and survival, ${ }^{33}{ }^{34}$ and the discovery of neutrophil specific isoforms makes selective therapeutic targeting with conventional small molecular weight inhibitors a realistic prospect. Certainly, the introduction of a $\Delta \mathrm{p} 85$ phosphoinositide 3-kinase construct delivered using an HIV-TAT based protein delivery system in mice has a dramatic protective effect on ovalbumin induced airways inflammation. ${ }^{35}$

Thus, while the role of the eosinophil in mediating airways inflammation in mild and moderate atopic asthma appears secure, ${ }^{36}{ }^{37}$ the importance of the neutrophil as perhaps the dominant inflammatory cell in many of the nonatopic and more severe phenotypes of 
asthma is now equally clear. Corticosteroids are highly effective in promoting the resolution of eosinophilic inflammation but far less so in neutrophilic inflammation and, indeed, may even facilitate the arrival and survival of these cells in the airway wall.

Thorax 2005;60:529-530.

doi: $10.1136 /$ thx.2005.043182

\section{Authors' affiliations}

A V Kamath, Department of Respiratory Medicine, Norfolk and Norwich University Hospital, Norwich, UK

I D Pavord, Institute of Lung Health, Glenfield Hospital, Leicester, UK

P R Ruparelia, E R Chilvers, Respiratory Medicine Division, Department of Medicine, University of Cambridge School of Clinical Medicine, Addenbrooke's and Papworth Hospitals, Cambridge, UK

Correspondence to: Professor E R Chilvers, Respiratory Medicine Division, Department of Medicine, University of Cambridge School of Clinical Medicine, Addenbrooke's Hospital Cambridge CB2 2QQ, UK; erc24@cam.ac.uk

The work in the authors' laboratories is supported by the Wellcome Trust, British Heart Foundation, Asthma UK, MRC, Papworth Hospital and the British Lung Foundation.

\section{REFERENCES}

1 Bousquet J, Chanez P, Lacoste JY, et al. Eosinophilic inflammation in asthma. NEngl J Med 1990;323:1033-9.

2 Fahy JV, Kim KW, Liu J, et al. Prominent neutrophilic inflammation in sputum from subjects with asthma exacerbation. J Allergy Clin Immunol 1995;95:843-52.

3 Turner MO, Hussack P, Sears MR, et al. Exacerbations of asthma without sputum eosinophilia. Thorax 1995;50:1057-61.

4 Douwes J, Gibson P, Pekkanen J, et al. Noneosinophilic asthma: importance and possible mechanisms. Thorax 2002;57:643-8.

5 Brightling CE, Symon FA, Birring SS, et al. Comparison of airway immunopathology of eosinophilic bronchitis and asthma. Thorax 2003;58:528-32.

6 Leckie MJ, Brinke A, Khan J, et al. Effects of an interleukin-5 blocking monoclonal antibody on eosinophils, airway hyper-responsiveness, and the late asthmatic response. Lancet 2000;356:2144-8.
7 Bryan SA, O'Connor BJ, Matti S, et al. Effects of recombinant human interleukin-12 on eosinophils, airway hyper-responsiveness, and the late asthmatic response. Lancet 2000;356:2149-53.

8 Kips JC, O'Connor BJ, Langley SJ, et al. Effect of SCH55700, a humanised anti-human interleukin5 antibody, in severe persistent asthma: a pilot study. Am J Respir Crit Care Med 2003; 167:1655-9

9 Humbles AA, Lloyd CM, McMillan SJ, et al. A critical role for eosinophils in allergic airways remodeling. Science 2004;305:1776-9.

10 Wenzel SE, Szefler SJ, Leung DYM, et al. Bronchoscopic evaluation of severe asthma: persistent inflammation associated with high dose glucocorticoids. Am J Respir Crit Care Med 1997;156:737-43.

11 Jatakanon A, Uasuf C, Maziak W, et al Neutrophilic inflammation in severe persistent asthma. Am J Respir Crit Care Med 1999; 160:1532-9.

12 Little SA, Macleod KJ, Chalmers GW, et al. Association of forced expiratory volume with disease duration and sputum neutrophils in chronic asthma. Am J Med 2002;112:446-52.

13 Wenzel SE, Schwartz LB, Langmack EL, et al. Evidence that severe asthma can be divided pathologically into two inflammatory subtypes with distinct physiologic and clinical characteristics. Am J Respir Crit Care Med 1999:160:1001-8.

14 Pavord ID, Brightling CE, Woltmann G, et al. Non-eosinophilic corticosteroid unresponsive asthma. Lancet 1999;353:2213-4.

15 Green RH, Brightling CE, Woltmann G, et al. Analysis of induced sputum in adults with asthma: identification of subgroup with isolated sputum neutrophilia and poor response to inhaled corticosteroids. Thorax 2002;57:875-9.

16 Martin RJ, Cicutto LC, Smith HR, et al. Airways inflammation in nocturnal asthma. Am Rev Respir Dis 1991;143:351-7.

17 Chalmers GW, Macleod KJ, Thomson L, et al. Smoking and airway inflammation in patients with mild asthma. Chest 2001;120:1917-22.

18 Anees W, Huggins V, Pavord ID, et al. Occupational asthma due to low molecular weight agents: eosionphilic and non-eosinophilic variants. Thorax 2002;57:231-6.

19 Sur S, Crotty TB, Kephart GM, et al. Sudden-onset fatal asthma: a distinct entity with few eosinophils and relatively more neutrophils in the airway submucosa? Am Rev Respir Dis 1993;148:713-9.

20 Gibson PG, Simpson JL, Saltos N. Heterogeneity of airway inflammation in persistent asthma: evidence of neutrophilic inflammation and increased sputum interleukin-8. Chest 2001;119:1329-36.

21 Stenfors N, Pourazar J, Blomberg A, et al. Effect of ozone on bronchial mucosal inflammation in asthmatic and healthy subjects. Respir Med 2002;96:352-8.

22 Lacoste JY, Bousquet J, Chanez P, et al. Eosinophilic and neutrophilic inflammation in asthma, chronic bronchitis, and chronic obstructive pulmonary disease. J Allergy Clin Immunol 1993:92:537-48.

23 Serra-Batlles J, Plaza V, Morejon E, et al. Costs of asthma according to the degree of severity. Eur Respir J 1998;12:1322-6.

24 Wark PAB, Johnston SL, Moric I, et al. Neutrophil degranulation and cell lysis is associated with clinical severity in virus-induced asthma. Eur Respir J 2002; 19:68-75.

25 Ordonez CL, Shaughnessy TE, Matthay MA, et al. Increased neutrophil numbers and IL-8 levels in airway secretions in acute severe asthma: clinical and biological significance. Am J Respir Crit Care Med 2000;161:1185-90

26 Hauber HP, Gotfried M, Newman K, et al. Effect of HFA-flunisolide on peripheral lung inflammation in asthma. J Allergy Clin Immunol 2003;112:58-63.

27 Tanizaki $\mathrm{Y}$, Kitani $\mathrm{H}$, Mifune $\mathrm{T}$, et al. Effects of glucocorticoids on humoral and cellular immunity and on airway inflammation in patients with steroid-dependent intractable asthma. J Asthma 1993;30:485-92.

28 Nguyen LT, Lim S, Oates T, et al. Increase in airway neutrophils after oral but not inhaled corticosteroid therapy in mild asthma. Respir Med 2005:99:200-7.

29 Cox G. Glucocorticoid treatment inhibits apoptosis in human neutrophils. Separation of survival and activation outcomes. J Immunol 1995:154:4719-25.

30 Meagher LC, Cousin JM, Seckl JR, et al. Opposing effects of glucocorticoids on the rate of apoptosis in neutrophilic and eosionophilic granulocytes. J Immunol 1996;156:4422-8.

31 Liu Y, Cousin JM, Hughes J, et al. Glucocorticoids promote nonphlogistic phagocytosis of apoptotic leukocytes. J Immunol 1999;162:3639-46.

32 Brazil TJ, Dagleish MP, McGorum BC, et al. Kinetics of pulmonary neutrophil recruitment and clearance in a natural and spontaneously resolving model of airway inflammation. Clin Exp Allergy 2005 (in press)

33 Cadwallader KA, Condliffe AM, McGregor A, et al. Regulation of phosphoinositide 3-kinase activity and $\operatorname{Ptd} \operatorname{lns}(3,4,5) \mathrm{P}_{3}$ accumulation by neutrophil priming agents. $J$ Immunol 2002;169:3336-44

34 Cowburn AS, Cadwallader K, Reed B, et al. Role of PI3-kinase dependent BAD phosphorylation and altered transcription in cytokine-mediated neutrophil survival. Blood 2002;100:2607-16.

35 Myou S, Leff AR, Myo S, et al. Blockade of inflammation and airway hyperresponsiveness in immune-sensitized mice by dominant-negative phosphoinositide 3-kinase-TAT. J Exp Med 2003;198: 1573-82.

36 Aalbers R, Kauffman HF, Vrugt B, et al. Allergeninduced recruitment of inflammatory cells in lavage 3 and $24 \mathrm{~h}$ after challenge in allergic asthmatic lungs. Chest 1993;103:1178-84.

37 Gauvreau GM, Watson RM, O'Byrne PM. Kinetics of allergen-induced airway eosinophilic cytokine production and airway inflammation. Am J Respir Crit Care Med 1999;160:640-7. 